\title{
Measurement of Flame Speeds by a Nozzle Burner Method ${ }^{1}$
}

\author{
Carl Halpern
}

\begin{abstract}
The literature records a great many measurements, using stationary flames on burners, of the speed with which flame moves through combustible mixtures of gases. Despite the fact that the method itself seems reasonably simple, the results obtained by various investigators often are not in good agreement. One of the phases of a program of research on combustion has been a study of some of the reasons for the differences among recorded values of flame speed measured by the burner method. The primary objective of this task has been to develop the precautions that should be observed in applying the method, rather than to evolve numerical values of flame speed. This paper describes progress that has been made since the apparatus was described originally in 1951, and presents values of flame speeds of methane-air mixtures obtained since then, together with comparisons of these values with those obtained by two flame theories.
\end{abstract}

\section{Introduction}

The capabilities and limitations of equipment designed for measuring flame speeds approaching the fundamental burning velocities have been described in previous publications $[1,2] .^{2}$ Briefly, this apparatus is designed for producing stable Bunsen-type flames above nozzles, from which the unburned mixture emerges at practically uniform velocity. Provision is made for varying and measuring initial mixture composition, temperature, and pressure, and for making direct and schlieren photographs of the inner flame cone. In the course of attempts to obtain values of burning velocity that are independent of the apparatus, a considerable number of the possible reasons for such dependence have been identified. Some of the disturbing factors have been eliminated and the effects of others have been reduced materially. It is hoped that this record of the precautions that have been found necessary in the measurement of burning velocities by a burner method may be useful to those who may choose to apply the method in the future.

\section{Apparatus}

The apparatus, patterned on that of Johnston [3], was described previously in reference [1], but since then numerous changes have been made to improve its performance. A brief description of the apparatus will be given and the major changes described fully. A schematic diagram is shown in figure 1. There are two separate systems for metering and controlling the rates of flow of fuel and air. The fuel is bottled methane, 99.65 percent pure; impurities are carbon dioxide, nitrogen, and ethane. Air is provided by the laboratory supply at $90 \mathrm{lb} / \mathrm{in}^{2}{ }^{2}$ gage. Each system comprises a pressure regulator, a drying unit, a thermocouple to measure gas temperature, a sharpedged orifice, a manometer to measure the pressure drop across the orifice, a manometer to measure pressure in the system, a flow controller, and a control valve. A micromanometer, read to 0.001 in.,

${ }_{1}$ The work described in this report was sponsored originally by the Bureau of Aeronautics, Department of the Navy.

${ }_{2}^{2}$ Figures in brackets indicate the literature references at the end of this paper. can be connected to read the pressure drop across either orifice. Standard well-type manometers, read to $0.01 \mathrm{in}$., are used to measure other pressures. The burner assembly comprises a stainless-steel approach tube, $38 \mathrm{in}$. long and $1 \frac{1}{2}$-in. i. d., a chamber for heating the gas mixture to a constant temperature and for smoothing the flow of the gas, and a nozzle. Fuel and air are mixed and introduced at the base of the approach tube. The calming chamber and nozzle are enclosed in a steel box, having plate-glass windows, which may be pressurized or evacuated. The double-pass noncoincidence schlieren system comprises an air-cooled mercury-vapor lamp, a collimating lens, a $90^{\circ}$ prism, a first knife edge, and 8-in. first-surface spherical mirror, a second knife edge, an image-forming lens, and a $35-\mathrm{mm}$ camera body.

Drying systems: Originally it was planned to use the fuel and air saturated with water vapor. But as the amount of water vapor in a gas depends on its temperature and pressure, both of which are variable, and the calibration of the orifices involves the density of the gas, it was decided to dry the fuel and air to avoid uncertainties caused by fluctuating water content. The drying system for air, which is first passed through a filter to remove scale and oil, comprises a column of activated alumina followed by a cold trap immersed in a slush of dry ice in a mixture of carbon
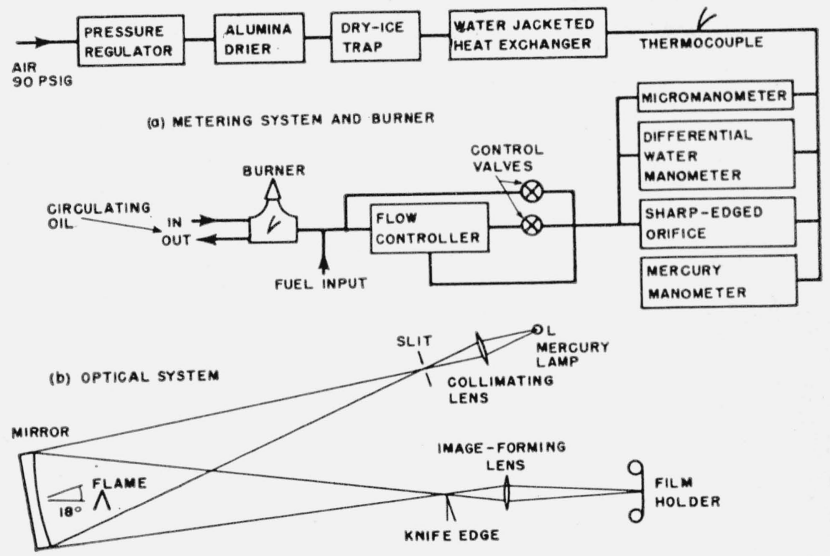

FIGURE 1. Schematic diagram of metering, drying and schlieren equipment, and nozzle assembly. 


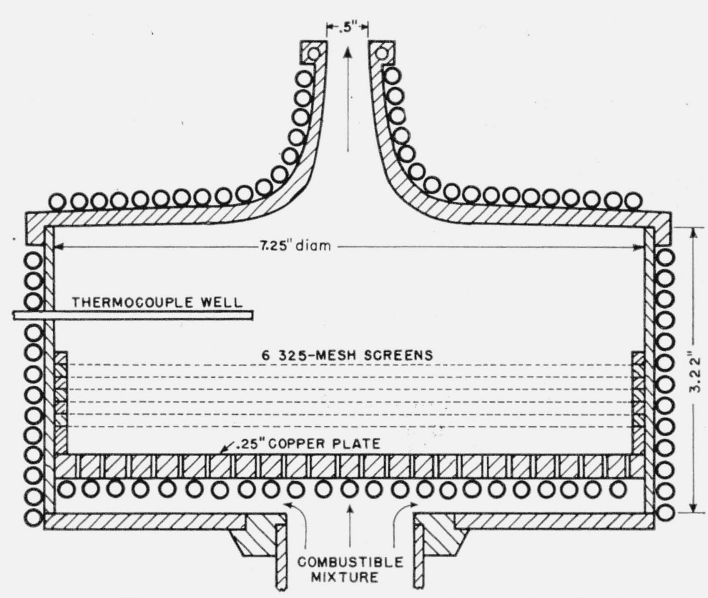

Figure 2. Constant temperature nozzle and calming chamber.

tetrachloride and chloroform at a temperature of about $-112^{\circ} \mathrm{F}$. The air is then warmed in a heat exchanger by tap water. The alumina column contains a built-in heating unit so the contents may be reactivated in place. The drying system for methane consists only of the cold trap and heat exchanger. Water content is thus kept at 0.03 percent by volume.

Orifices: The sharp-edged orifices were recalibrated several times because some discrepancies in calculated rate of gas flow were discovered. Calibrations obtained after correcting for or eliminating all known sources of error are felt to be accurate to about 0.5 percent. Orifices of extended range for use with larger nozzles, and new improved orifice holders have been built. Thermocouples made from specially calibrated wire are used to measure gas temperatures. Emf from these couples is measured by a precision electronic potentiometer to about $1 \mu \mathrm{v}$, or $0.04^{\circ} \mathrm{F}$.

The constant-temperature calming chamber and nozzle are shown in figure 2. Three nozzles of $1 / 2^{-}$, $3 / 4^{-}$, and $1 \frac{1}{1 / 6}$-in. port diameter were built. The combustible mixture enters the chamber from the burner tube, passes through the perforated plate, consisting of spirally wound coils of $3 / 16$-in. copper tubing, hard soldered to the under side of a copper disk, through copper gauze screens into the calming region above, and out through the nozzle. The nozzle and cylindrical sides of the chamber are wound with copper tubing, which is hard soldered to the surfaces. The lip of the nozzle contains a channel connected in series with the coils. The three coils that completely envelop the calming chamber and nozzle are manifolded and insure that the entire volume above the copper plate is practically isothermal. A thermocouple well made of 18-8 stainless steel tubing 0.090 in. o. d. and 0.010-in. wall thickness is mounted in the geometric shadow of the nozzle and is silver plated to decrease the effects of radiation. The hot thermostatically controlled fluid circulated through the coils is Plexol 201, a proprietary synthetic lubricant. The maximum temperature that can be used, about $350^{\circ} \mathrm{F}$, is considerably below the boiling point of the liquid, which is about $500^{\circ} \mathrm{F}$. Cavitation in the pump used to circulate the liquid appears to be the limiting factor. Temperature of the gas flowing through the calming chamber and nozzle can be controlled to $\pm 0.5^{\circ} \mathrm{F}$.

When the $1 / 2$-in. nozzle and calming chamber were first put to use, turbulence induced by the gas issuing from the perforated copper plate resulted in a disturbed flame. A layer of glass wool on the copper plate retained by a 60 -mesh copper screen was sufficient to smooth out inequalities in the gas flow through the $1 / 2$-in. nozzle. These measures were inadequate for the $3 / 4$-in. nozzle, and it was necessary to use two 325-mesh screens above the plate and partly to stuff the approach tube with steel wool. The 1/16-in. nozzle could not be placed in service because a flame of required quality could not be formed despite many attempts to smooth the gas flow. The measures taken to improve the gas flow through this large nozzle, however, greatly improved the performance of the smaller nozzles. The perforated copper plate in the calming chamber was redesigned and lowered. Six 325-mesh screens and spacers were installed, and the use of glass and steel wool was discontinued. It is felt that improperly smoothed gas flow rather than any inherent instability of large flames is the cause of the failure to obtain a satisfactory flame on the 11/16-in. nozzle.

Schlieren system: A condenser discharge type of power supply to supplement the original power supply for the mercury-vapor lamp was built to provide a high-intensity flash to permit the study of disturbed flames. A 1- $\mu \mathrm{f}$ condenser is charged to 2,800 $\mathrm{v}$ and discharged through the lamp. An auxiliary series gap, ionized by an automobile spark coil, is used to insulate the capacitor until the flash is desired. A flash with a duration of about $30 \mu \mathrm{sec}$ is obtained.

A $35-\mathrm{mm}$ camera is used to photograph the flame, and all measurements are made from enlargements, which are printed on aerial mapping paper having a minimum of shrinkage. Only the body and the focal plane shutter of the camera are used. The camera lens is removed, and an achromatic lens of $60-\mathrm{cm}$ focal length, placed a suitable distance behind the second knife edge, forms the image on the plane of the film in the camera. To record the visible and schlieren images simultaneously on the same film, the intensity of the light from the lamp is decreased by a variable-density filter until the two images are equal in intensity in the view finder of the camera. A section of a machinist's scale is positioned on the nozzle and photographed so the exact size of the photographed flames can be determined.

\section{Measurement of Burning Velocity}

The true burning velocity is the velocity of propagation of a flame, normal to the flame front, relative to the unburned mixture. It is thus a property of the mixture of fuel and oxidant, and of the physical condition of the mixture and is independent of the apparatus in which it is measured. Ideally, if the veloclty of the unburned gas issuing from the port of a burner is uniform and the gas flow is parallel to the axis of the burner, the flame 


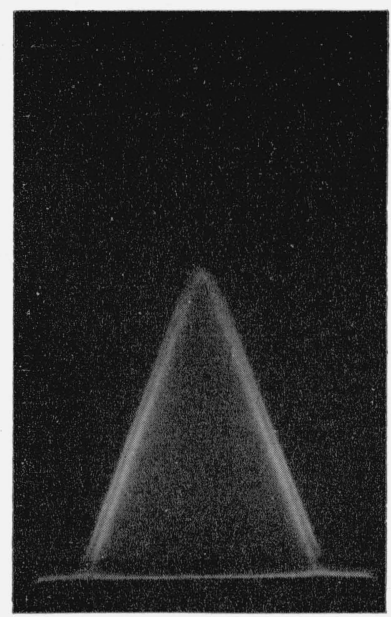

Figure 3. Typical methane-air flame above a nozzle burner.

front is a perfect right cone. The true burning velocity is then equal to the component of the velocity of the unburned gas, which is perpendicular to an element of the cone, and is given by

$$
S_{f}=U_{u} \sin \alpha,
$$

where $S_{f}$ is the true burning velocity; $U_{u}$, the velocity of the unburned gas; and $\alpha$, one-half the angle of the apex of the flame cone.

Because the values reported in the literature as true burning velocity differ so widely, obviously factors other than properties of the combustible mixtures or their physical conditions have influenced the determinations. These cannot therefore be considered true burning velocities with any degree of accuracy, and until effects of these disturbing factors have been shown to be either eliminated or minimized, values presented here will be termed flame speeds.

As described in reference [1], flame speeds were first calculated, using eq (1), from a group of observations in which the image of the schlieren cone was projected on a ground-glass screeen, and its apex angle was measured directly by a goniometer. The results showed a variation of flame speed with gas velocity of 30 percent over the range of gas velocities of 3 to $5 \mathrm{fps}$, and are inconsistent with the concept of burning velocity as a property of the mixture and its state only.

At this point, a photographic study of flames was begun. Figure 3 is a photograph of a typical methane-air flame atop a nozzle burner, showing both the luminous and schlieren images taken simultaneously. The bases of both the schlieren and visible cones were found to be larger than the diameter of the port. The base of the schlieren cone, which is defined by extending straight lines through the center of the schlieren trace to the top of the burner, was found to vary both with the velocity of the gas and with the fuel-air ratio. ${ }^{3}$ The diameter

${ }^{3}$ Fuel-air ratio $(F / A)$ is defined as the ratio of the weight of fuel to the weight of air in the combustible mixture.

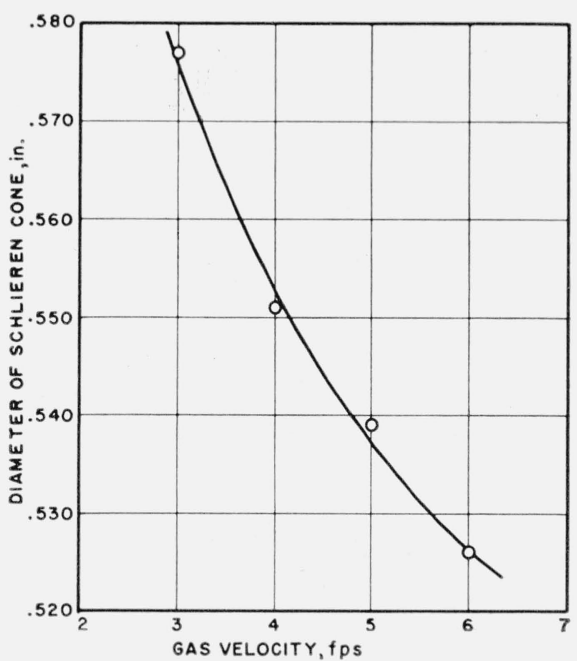

FIGURE 4. Variation of diameter of base of schlieren cone with gas velocity, $F / A=0.058, T_{n}=75^{\circ} F$.

of the base of the schlieren cone decreases as the gas velocity increases, and this effect is illustrated in figure 4. Using a nearly stoichiometric fuel-air mixture $(F / A)$, at a constant nozzle temperature, $\left(T_{n}\right)$, the diameter of the base of the schlieren cone, $\left(D_{c}\right)$, was 0.573 in at a gas velocity of $3 \mathrm{fps}$ but decreased to $0.521 \mathrm{in}$. at a gas velocity of $7 \mathrm{fps}$. The slight increase in diameter of the base of the schlieren cone with fuel-air ratio is illustrated in figure 5 . At a constant gas velocity of $6 \mathrm{fps}$ and a fuel-air ratio of 0.057 , the diameter of the base of the cone was 0.526 in., whereas at fuel-air ratio of 0.067 , the diameter was 0.531 . Temperature of the combustible mixture was about $75^{\circ} \mathrm{F}$. The diameter of the port of the nozzle is 0.504 in. at room temperature.

Previous tests had shown the flow of gas issuing from the nozzle in the absence of burning to be uniform and the velocity profile to be flat, so that this lateral expansion, which leads to an increase in the diameter of the base of the flame cone, must be caused by burning. Particle track studies [4] of burner flames show that the gas flow tends to diverge from parallel both at the rim of the burner and in the preheat region just ahead of the zone of combustion. It is widely considered that quenching of flame occurs at the rim of a burner, which acts as a sink for heat and active particles, and quenching may affect the flow of the gas. There exists a dark space just above the rim into which some of the combustible mixture may flow. It is also conceivable that air may infil-

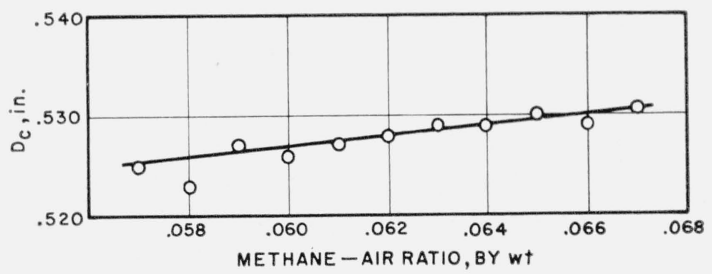

Figure 5. Variation of diameter of base of schlieren cone with fuel-air ratio, $U_{u}=6 \mathrm{fps}, T_{n}=75^{\circ} \mathrm{F}$. 
trate into the dark space, cooling the gas and lowering the flame speed adjacent to the nozzle. The flow of gas through the nozzle, especially at low velocities, may be subject to the "teapot effect" [5], in which the effluent gas clings to and flows along the rim of the nozzle.

Because eq (1), which requires measurement of only gas velocity and the angle of the flame cone, does not yield reliable values of flame speeds, a means was sought to improve the reliability of the results. It was found that if eq (1) is modified by the empirical factor $\left(D_{n} / D_{c}\right)^{2}$, where $D_{n}$ is the diameter of the port of the burner, and $D_{c}$ is the diameter of the base of the schlieren cone, giving

$$
S_{f}=U_{u}\left(\frac{D_{n}}{D_{c}}\right)^{2} \sin \alpha,
$$

the flame speed shows relatively little variation with gas velocity. Equation (2) is merely another way of expressing the well-known area method of calculating flame speeds:

$$
S_{f}=V / A,
$$

where $V$ is the volumetric rate of flow of the unburned gas, and $A$ is the surface area of the flame. For purposes of calculation, eq (3) may be written as

$$
S_{f}=\frac{4 V}{\pi D_{c}^{2}} \sin \alpha \text {. }
$$

"This requires a measurement of the angle of the apex of the schlieren cone and the diameter of the base of the schlieren cone. Use of eq (4) (termed the perfect cone technique) reduced the variation of flame speed with gas velocity from 30 percent over the range of gas velocities of 3 to $5 \mathrm{fps}$ to about 4 percent over the increased range of 3 to $7 \mathrm{fps}$, at a gas temperature of about $75^{\circ} \mathrm{F}$. Improvements to the burner and gasmeasuring systems further decreased this variation.

Another method of determining the total area, called the "planimeter technique," is based on a method described by Albright, Heath, and Thena [6]. Here, the surface area of the flame cone is calculated by

$$
A=\pi A_{1} l / h,
$$

where $A_{1}$ is the area, determined by a planimeter, of the vertical cross section of the schlieren cone as seen on a photograph of a flame; $l$, the slant height of the cone; and $h$, the height of the cone. Equation (5) can be transformed to

$$
A=\frac{\pi}{4}\left(16 A_{1}^{2}+D_{c}^{4}\right)^{1 / 2},
$$

where only $A_{1}$, the area of a vertical cross section of the flame cone, and $D_{c}$, the diameter of the base of the schlieren cone, need be measured. The value of $A$ so determined is substituted in eq (3) to determine $S_{f}$.

Equations (6) and (4) assume that the flame surface is a pertect right cone, and the closer the flame is to this ideal, the more nearly will these equations apply. The planimeter technique appears to be more accurate for determining surface areas of flames at low gas velocities than the perfect-cone technique. At low gas velocities the sides of the flame cone are somewhat curved, and it is difficult to select a straight line to represent the flame front; in fact, this is theoretically impossible. With only a slight curvature, however, the assumption of a perfect cone leads to a reasonably close approximation. Areas obtained with the planimeter are usually somewhat smaller than those calculated by the perfect-cone technique and lead to higher flame speeds. The most nearly theoretically exact method of measuring areas of flame surfaces that depart appreciably from conical, to divide the surface into a large number of segments and to sum those areas, is unfortunately laborious and difficult. Precision will decrease as measurements progress from the base to the tip because the image of the cone is somewhat diffuse. When such measurements have been made, the total area has been found to be smaller than that calculated by the perfect-cone method.

Results obtained with the planimeter technique still show a variation of flame speed with gas velocity, but the variation is linear, and the measured flame speed decreases with increasing gas velocity. A comparison of flame speeds obtained by the perfectcone and planimeter techniques is presented in figure 6 . The observed difference ranges from a minimum of about 0.4 percent at a gas velocity of

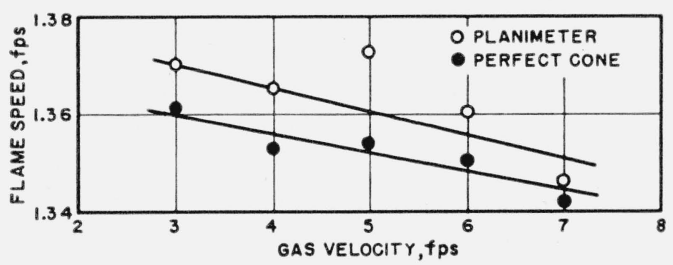

Figure 6. Comparison of flame speeds obtained by the planimeter and perfect cone methods, $F / A=0.062, T_{n}=112^{\circ} F$, diameter of nozzle $=3 / 4$ in.

7 fps to about 1.4 percent at $5 \mathrm{fps}$. If, however, we ignore the observation by the planimeter method at $5 \mathrm{fps}$, which appears to be out of line with the rest, the maximum difference remaining is less than 1 percent. Best results by either method indicate that the variation of flame speed with gas velocity has been reduced to about 1.5 percent in this range. Precision of measurement is the same in both techniques, about 0.25 percent. This small variation may be a result of averaging the flame speed over the entire flame surface. Near the tip of the flame cone, because of the strong curvature, the flame speed is probably highest; whereas at the base, due to the presence of the burner rim, it is lowest [7].

\section{Some Factors Affecting Flame Speeds}

\subsection{Gas Temperature}

Some of the heat liberated by a flame is inevitably transferred to the burner and thence to the gas that 


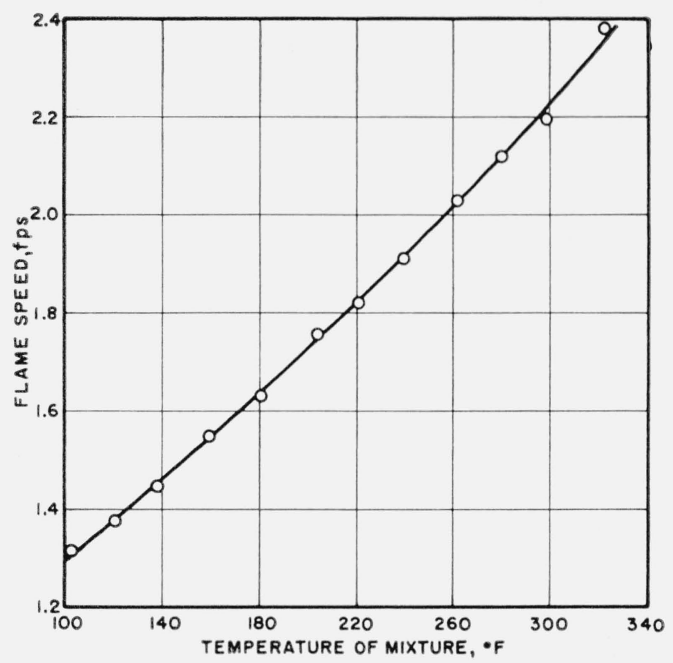

Figure 7. Variation of flame speed with gas temperature, $F / A=0.062, U_{u}=6 \mathrm{fps}$, diameter of nozzle $=1 / 2 \mathrm{in}$.

is flowing through it. Thus thermal gradients may be set up, with the gas nearest the wall being the hottest, and the over-all temperature of the combustible mixture at the burner will be higher than the temperatures of the fuel and air measured upstream. Any calculation of volume rate of flow that ignores this heating will be in error. The temperature gradient may lead to a distorted flame. Use of a constant-temperature nozzle and calming chamber is an attempt to insure that the temperature of the gas in the nozzle is known and that thermal gradients are at a minimum. As shown in figure 7, the flame speed is greatly affected by the initial temperature of the combustible mixture. (The flame speeds reported hereafter are averages of the values obtained by the perfect cone and planimeter techniques.) Over the range $100^{\circ}$ to $325^{\circ} \mathrm{F}$, the variation of flame speed with initial temperature is nearly linear and amounts to $0.0048 \mathrm{fps} /{ }^{\circ} \mathrm{F}$. At $100^{\circ} \mathrm{F}$, the flame speed is $1.305 \mathrm{fps}$, whereas at $320^{\circ} \mathrm{F}$, it is $2.361 \mathrm{fps}$. The fuel-air ratio was 0.062 , approximately the value for maximum flame speed, during this series of observations, and the unburned gas velocity was $6 \mathrm{fps}$. In view of this relationship between flame speed and initial temperature, the initial temperature of the combustible mixture must be controlled and specified if reported values of flame speeds are to have any significance.

\subsection{Mixture Ratio}

The variation of flame speed with mixture ratio at constant gas velocity was determined for three initial gas temperatures. The $3 / 4$-in. nozzle was used, and the gas velocity was $6 \mathrm{fps}$. The fuel-air ratio was varied from 0.054 to 0.072 , and gas temperatures of $84.4^{\circ}, 100^{\circ}$, and $120^{\circ} \mathrm{F}$ were used. A gas temperature of $84.4^{\circ} \mathrm{F}$ is the lowest that can be maintained at the nozzle by circulating oil, which is cooled in a heat exchanger by tap water. Results of these experiments are shown in figure 8 . The maximum flame speed is found at a fuel-air ratio close to 0.062 , and there seems to be no definite displacement with

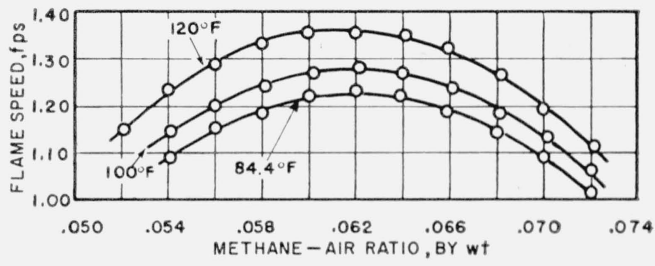

Figure 8. Effect of fuel-air ratio on flame speed at three unburned gas temperatures, $U_{u}=6 \mathrm{fps}$, diameter of nozzle $=$ $3 / 4$ in.

temperature over the limited range covered here.

Further measurements were made of flame speeds of methane-air mixtures at gas temperatures at the burner nozzle of $280^{\circ}$ and $330^{\circ} \mathrm{F}$, using the $1 / 2$-in. nozzle. The velocity of the gas in the nozzle was varied from 4 to $7 \mathrm{fps}$ at $280^{\circ} \mathrm{F}$ and from 5 to 10.2 fps at $330^{\circ} \mathrm{F}$. The fuel-air ratio was varied from 0.054 to 0.072 except at a gas velocity of $10.2 \mathrm{fps}$ and a temperature of $330^{\circ} \mathrm{F}$, where the leanest mixture that would burn was at fuel-air ratio 0.056 ; below this, the flame blew off the nozzle. Variation of flame speed with fuel-air ratio at constant gas velocity and at $280^{\circ} \mathrm{F}$ is shown in figure 9 , and at $330^{\circ} \mathrm{F}$ in figure 10 . The maxima are seen to have shifted at the higher temperatures to slightly richer mixture ratios. The large effect of mixture ratio on flame speed is, of course, obvious, and emphasizes the fact that the fuel-air ratio must be specified in
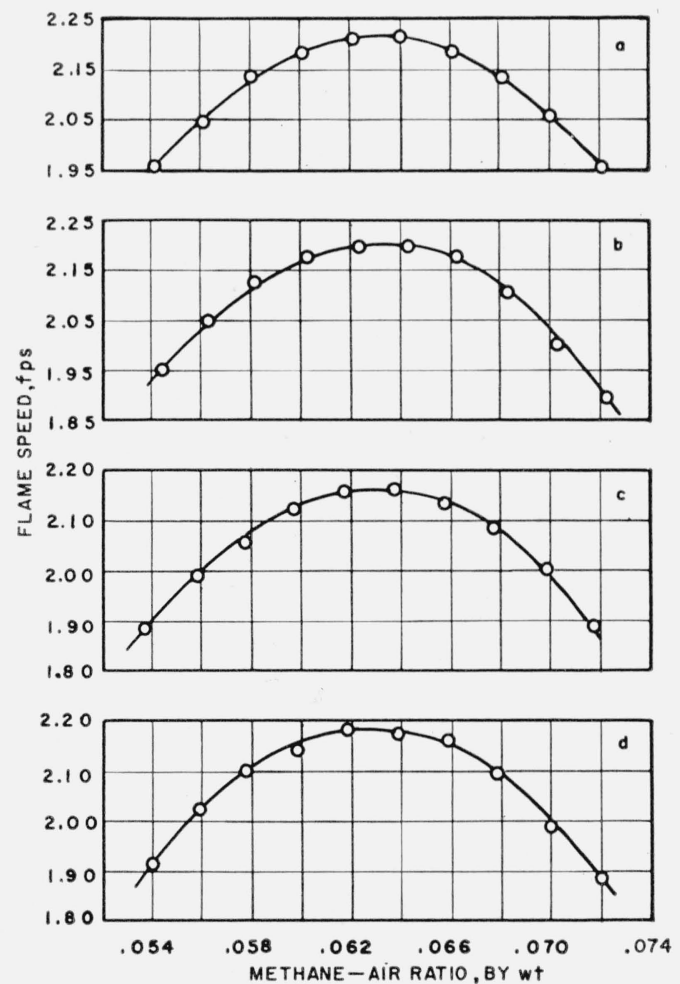

Figure 9. Effect of fuel-air ratio on flame speed at constant gas velocity.

$T_{n}=280^{\circ} \mathrm{F} ; U_{\mathrm{s}}=$ (a) $4 \mathrm{fps}$; (b) $5 \mathrm{fps}$; (c) $6 \mathrm{fps}$; (d) $7 \mathrm{fps}$. Diameter of nozzle = $1 / 2$ in. 

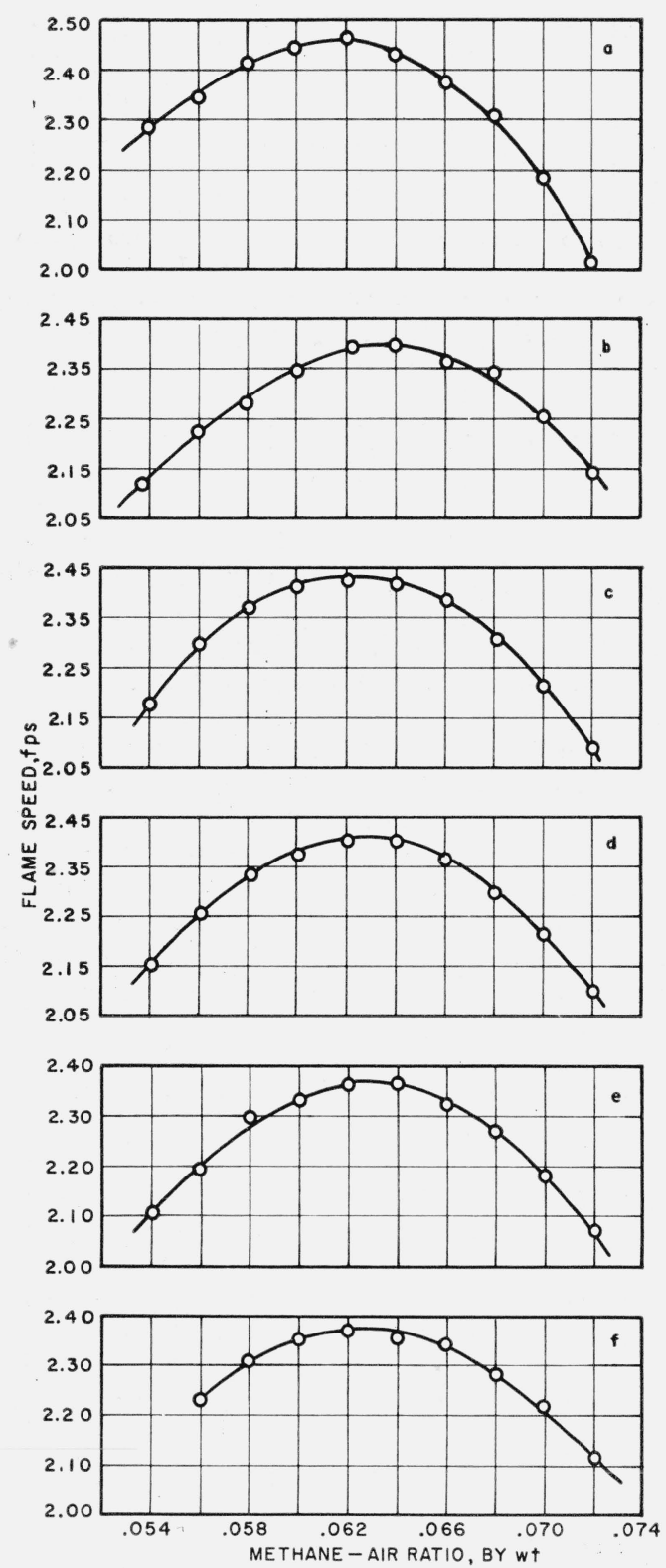

Figure 10. Effect of fuel-air ratio on flame speed at constant gas velocity.

$T_{n}=330^{\circ} \mathrm{F} ; U_{u}=$ (a) $5 \mathrm{fps}$; (b) 6 fps; (c) 7 fps; (d) 8 fps; (e) 9 fps; (f) 10.2 fps Diameter of nozzle $=1 / 2$ in.

defining a value of flame speed. The maximum flame speeds and the fuel-air ratios at which these maxima occur, at various gas velocities, are shown in table 1.

\subsection{Gas Velocity}

If, as mentioned earlier, the measured flame speed or burning velocity is a property of the combustible mixture only, and is not influenced by the burner or associated equipment, the values obtained will be expected to be independent of the gas velocity, $U_{u}$. That the measured values are not independent of gas velocity is shown in figures 11 and 12 , where flame speeds obtained at initial mixture tempera-
TABLE 1. Maximum flame speeds at given fuel-air ratios

\begin{tabular}{|c|c|c|c|}
\hline Gas velocity & $\begin{array}{c}\text { Fuel-air } \\
\text { ratio for } \\
\text { maximum } \\
\text { flame speed }\end{array}$ & $\begin{array}{l}\text { Gas temper- } \\
\text { ature }\end{array}$ & Flame speed \\
\hline $\begin{array}{c}\quad f p s \\
6 \ldots \\
6 \\
6 \\
4 \\
5 \\
6 \\
7 \\
5\end{array}$ & $\begin{array}{r}0.0619 \\
.0621 \\
.0618 \\
.0634 \\
.0636 \\
.0627 \\
.0628 \\
.0623 \\
.0632 \\
.0627 \\
.0630 \\
.0632 \\
.0628\end{array}$ & $\begin{array}{c}\circ F \\
84.4 \\
100 \\
120 \\
\\
280\end{array}$ & $\begin{array}{r}f p s \\
1.233 \\
1.283 \\
1.364 \\
2.212 \\
2.201 \\
2.164 \\
2.180 \\
2.457 \\
2.400 \\
2.426 \\
2.406 \\
2.372 \\
2.360\end{array}$ \\
\hline
\end{tabular}
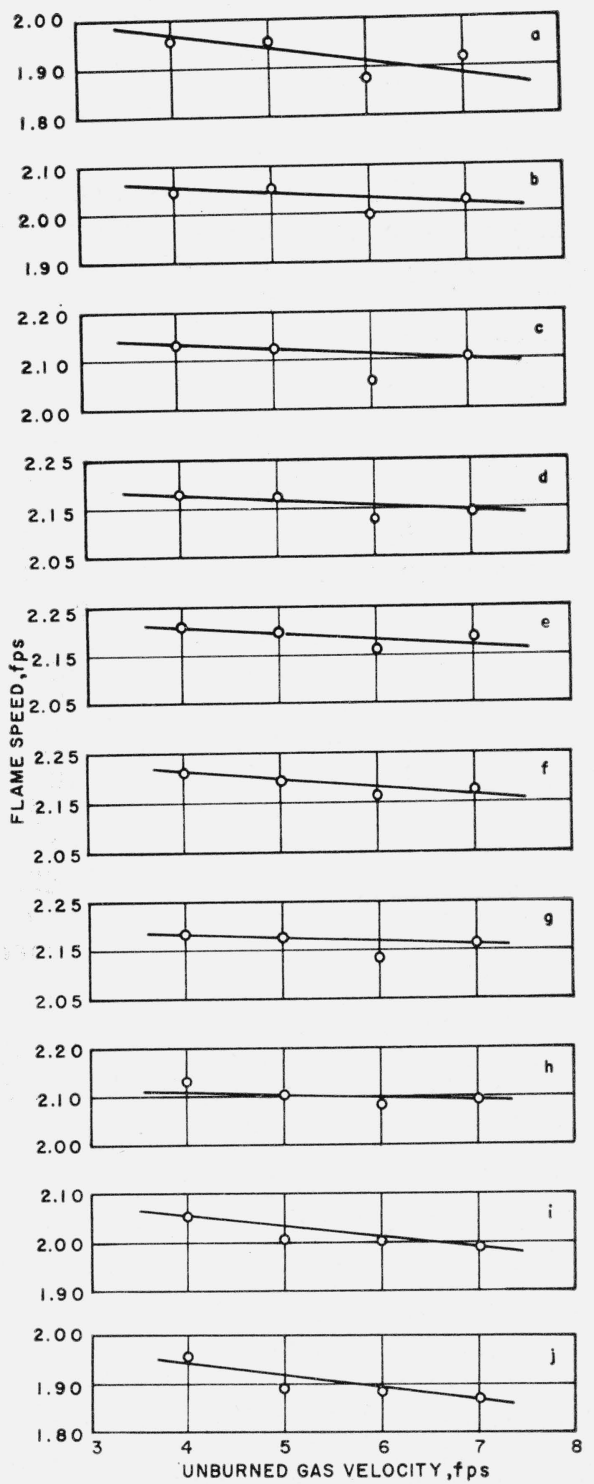

Figure 11. Effect of gas velocity on flame speed at constant fuel-air ratio.

$T_{n}=280^{\circ} \mathrm{F} ; F / A=$ (a) 0.054 ; (b) 0.056 ; (c) 0.058 ; (d) 0.060 ; (e) 0.062 ; (f) 0.064 (g) 0.066 ; (h) 0.068 ; (i) 0.070 ; (j) 0.072 . Diameter of nozzle $=1 / 2$ in. 

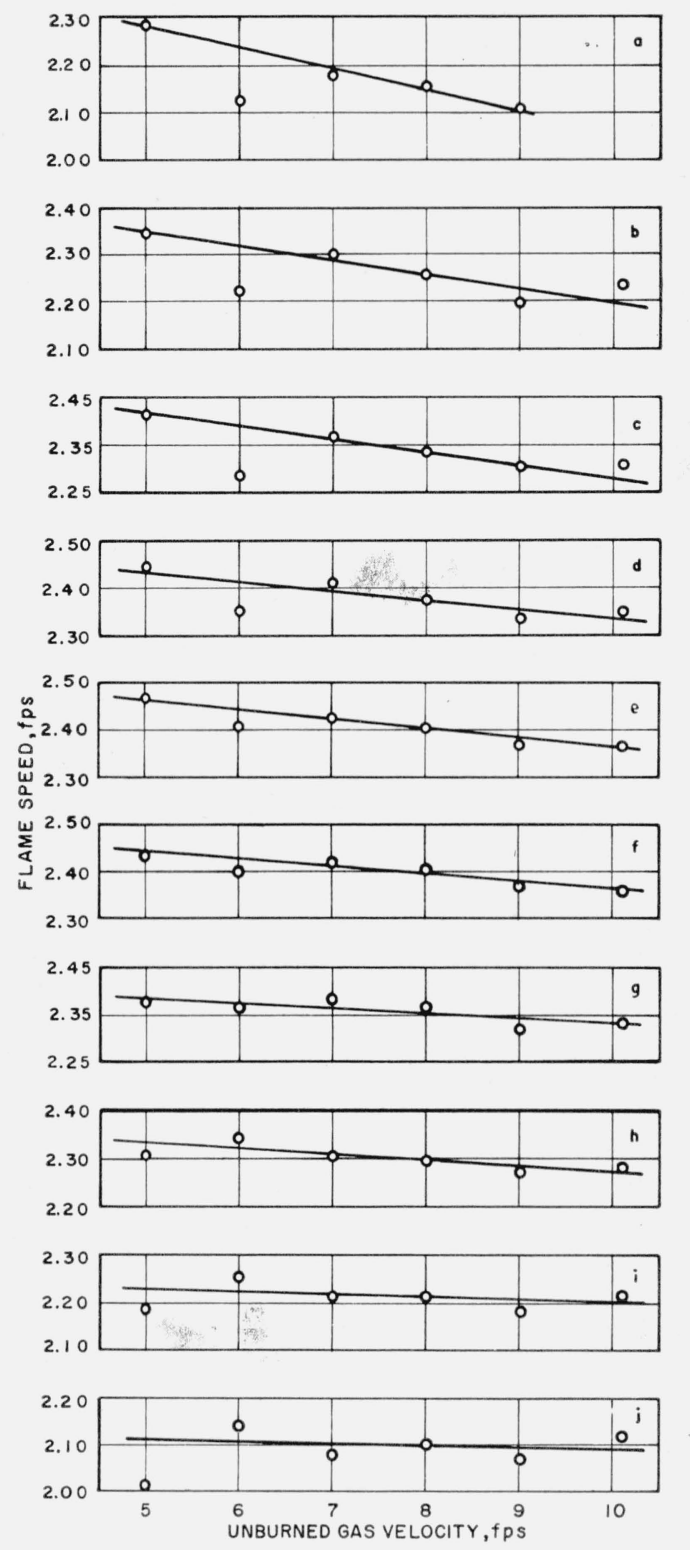

Figure 12. Effect of gas velocity on flame speed at constant fuel-air ratio.

$T_{n}=330^{\circ} \mathrm{F} ; F / A=$ (a) 0.054 ; (b) 0.056 ; (c) 0.058 ; (d) 0.060 ; (e) 0.062 ; (f) 0.064 (g) 0.066 ; (h) 0.068 ; (i) 0.070 ; (j) 0.072 . Diameter of nozzle $=1 / 2$ in.

tures of $280^{\circ}$ and $330^{\circ} \mathrm{F}$, respectively, are seen to decrease in practically all cases as gas velocity increases. Reasons for this dependence on gas velocity are obscure, but changes in apparatus and analytical methods described above have reduced the variations from as much as 30 percent to those found here.

Variation of flame speed with gas velocity at the lower temperatures was about 1.5 percent on the average, increased to about 2 percent at a gas temperature of $280^{\circ} \mathbf{F}$, and increased still further to an average of about 3.5 percent at a temperature of $330^{\circ} \mathrm{F}$. This increase with temperature may be a result of increased convection in the air surrounding the flame induced by the temperature difference between the air and the nozzle. Stability of the flame may have been affected by this increased convection.

The greatest variation of flame speed with gas velocity at $330^{\circ} \mathrm{F}$ was about 7.5 percent over the range of gas velocities from 5 to $9 \mathrm{fps}$ at a fuel-air ratio of 0.054 . This decreased as the mixture became richer, to about 5 percent at 0.056 , and to 1 percent at a ratio of 0.066 . The mixture apparently is near the lean blow-off limit at a mixture ratio of 0.054 because this mixture would not burn at $10.2 \mathrm{fps}$, so the values at 0.054 may not be trustworthy. If these values are disregarded, the average variation at a gas temperature of $330^{\circ} \mathrm{F}$ of flame speed with gas velocity is about 2.8 percent.

\subsection{Nozzle Size}

Variation of flame speed with gas velocity may be due in part to quenching of the flame by the burner rim. If the size of the burner port is increased, it might be expected that this variation would be reduced because the ratio of burner rim to flame area decreases as the diameter of the port increases. Earlier workers [8] had reported that the size of the burner does affect the flame speed, although their burners were much smaller than the ones used in the present work. It has also been suggested that there exists a size above which the flame speed is no longer affected. The nozzle with the $3 / 4$-in. port was built to test this suggestion, and the results with it were compared with those obtained with the $1 / 2$-in. nozzle. First results indicated that measured flame speeds were higher with the $3 / 4$-in. nozzle, and that the variation of flame speed with gas velocity was reduced over the range of gas flow from 3 to $7 \mathrm{fps}$. When, however, the gas flow was improved, oscillations were eliminated, and better control of gas temperature was established, the results showed no appreciable difference between the two nozzles. The variation of flame speed with gas velocity was about 1.5 percent in both over the range of gas velocities from 3 to $7 \mathrm{fps}$.

\subsection{Oscillations}

Oscillations were encountered in the flames during attempts to place the $3 / 4$-in. and $1 \frac{1}{16}-$ in. nozzles in operation. At times the tip of the flame cone fluctuated wildly, and a low-pitched buzzing was heard. To investigate this, a study of disturbed flames was made in which photographs, some of which are shown in figure 13 , were taken at exposure times of $1 / 1000$ sec and 5 sec at gas velocities of $3,4,5,6$, and 7 fps. Photographs taken at $1 / 1000$ sec, which show only the schlieren image, are sharp, whereas those taken at 5 sec have the added visible image and are rather blurred; the taller flames are most disturbed. Because the camera has a focal plane shutter, what is seen in these pictures is a combination of the motion of the flame and the shutter.

High-speed motion pictures of these flames showed a series of pulsations beginning at the basenand traveling up to the tip of the flame cone. Figure 14 shows the appearance of these pulsations in a picture 

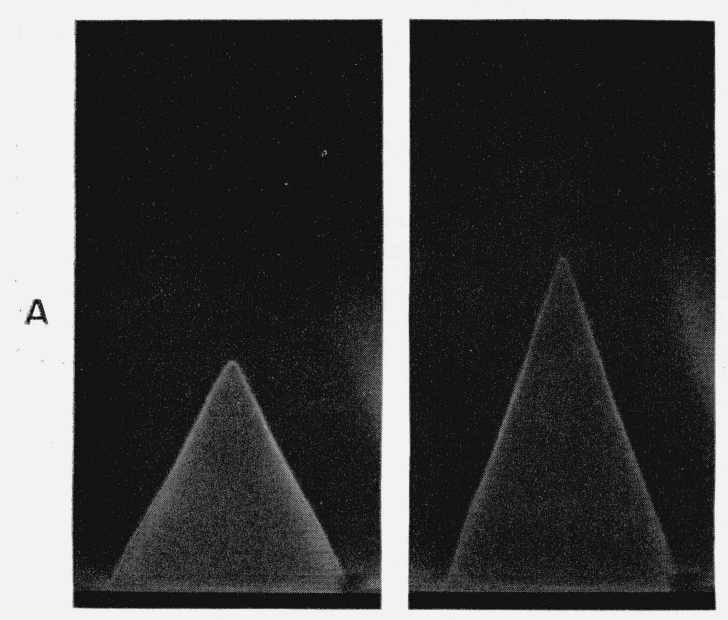

।
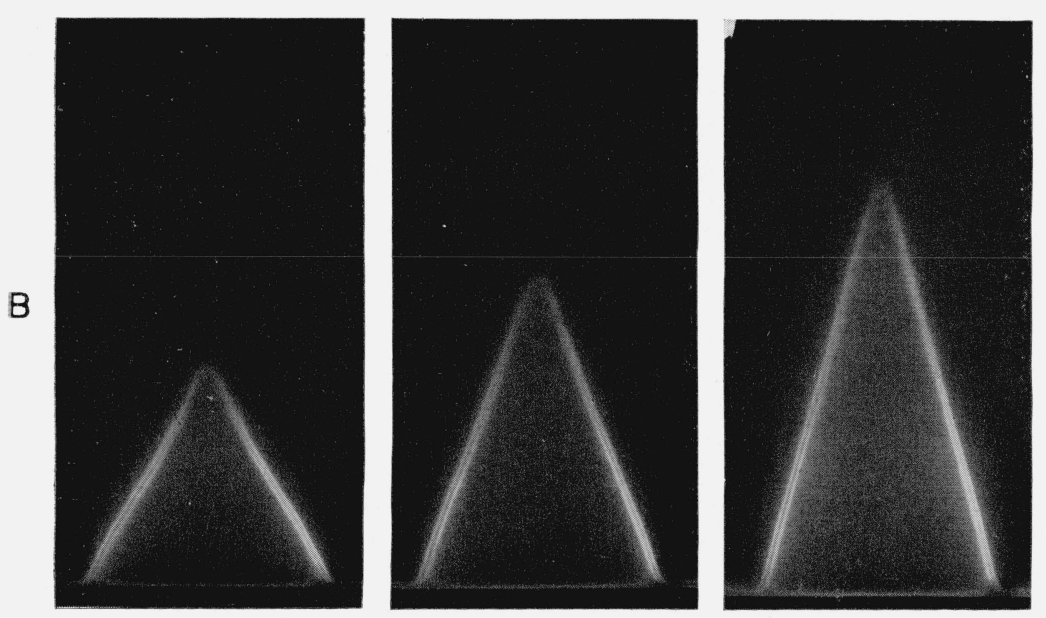

\section{3}

Figure 13. Disturbed flames taken at (a) 0.001 and (b) 5-sec exposure time.

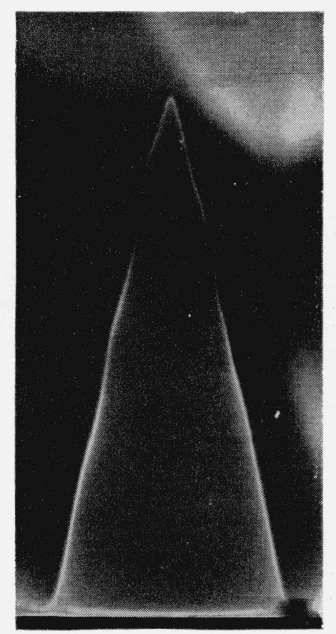

4

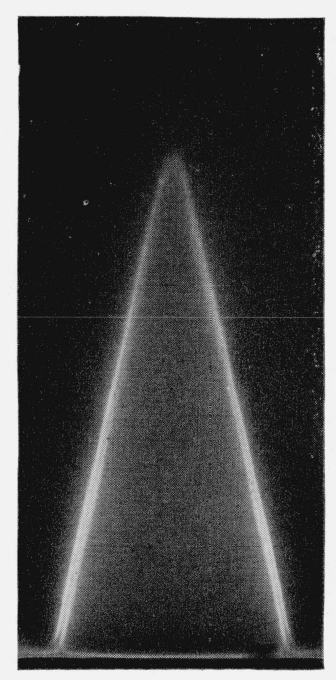

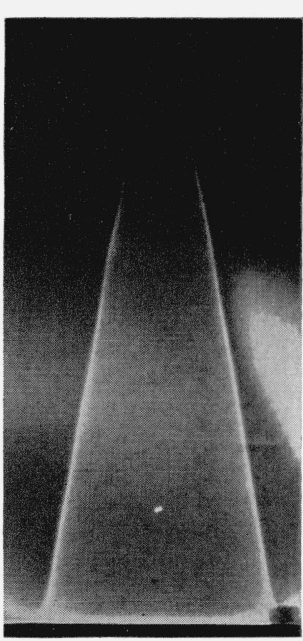

5

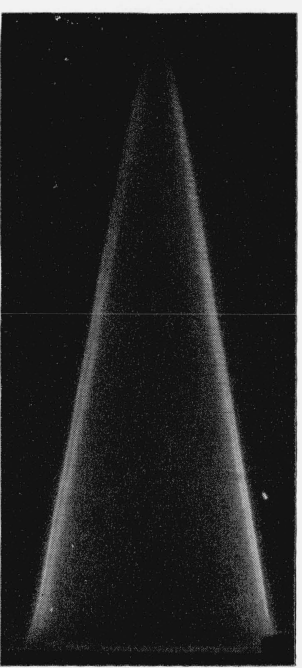

Gas velocity=(1) $3 \mathrm{fps}$; (2) $4 \mathrm{fps}$; (3) $5 \mathrm{fps}$; (4) $6 \mathrm{fps}$; (5) $7 \mathrm{fps}$.

of a schlieren cone, taken by a high-intensity flash. The pulsations were removed completely from the flame by lining the burner enclosure with acoustic tile.

Comparison of oscillating and quiescent flames show that there is less scatter in measurements made on quiescent flames, but no significant difference is seen in the magnitudes of flame speeds derived from measurements of instantaneous photographs of the two types of flames. There is no difference in values obtained from instantaneous and time photographs of quiescent flames, but flame speeds obtained from time exposures of oscillating flames are excessively high. This latter effect may be caused by the increased intensity of the schlieren image, due to the horizontal knife edge, which results when the inclination of the side of the cone increases as a pulse travels up the cone. A time exposure of an oscillating flame thus would have greater intensity toward the inner edge of its blurred image and give the appearance of a smaller flame.

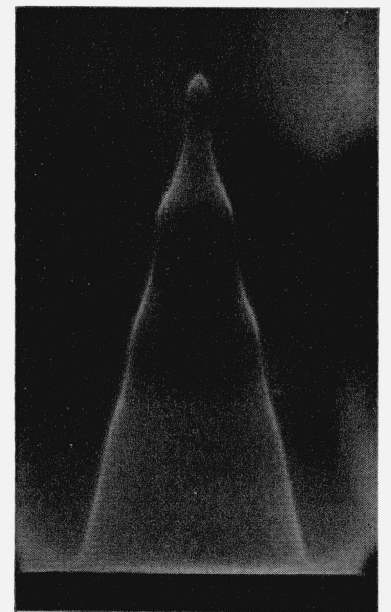

Figure 14. Oscillating methane-air flame. 


\section{Comparison of Experiment With Theories}

The variation of flame speed with initial temperature had been determined for a methane-air mixture, $F / A=0.062$, at a gas velocity of $6 \mathrm{fps}$ for the temperature range $312.5^{\circ}$ to $434.9^{\circ} \mathrm{K}\left(102.7^{\circ}\right.$ to $323.1^{\circ}$ $\mathrm{F}$ ), and data were thus available for a comparison of the experimental results with those predicted by Semenov's thermal theory and Tanford and Pease's diffusion theory. Semenov's equation [9] for flame speed, assuming a bimolecular reaction, is

$$
\begin{aligned}
S_{f}=\left[\frac{2 \lambda_{f} K a_{o} c_{p(f)}{ }^{2}}{\bar{c}_{p}{ }^{3}}\left(\frac{T_{o}}{T_{f}}\right)^{2}\left(\frac{\lambda}{c_{p} \rho D_{f}}\right)^{2}\right. \\
\\
\left.\left.\qquad \frac{n_{1}}{n_{2}}\right)^{2}\left(\frac{R T_{f}^{2}}{E}\right)^{3} \frac{e^{-E / R T_{f}}}{\left(T_{f}-T_{o}\right)^{3}}\right]^{1 / 2},
\end{aligned}
$$

where

$T_{0}=$ initial temperature, ${ }^{\circ} \mathrm{K}$

$T_{f}=$ flame temperature, ${ }^{\circ} \mathrm{K}$

$\rho=$ density of gas mixture, $\mathrm{g} / \mathrm{cm}^{3}$

$\lambda_{f}=$ thermal conductivity at $T_{f}, \mathrm{cal} / \mathrm{cm} \mathrm{sec}{ }^{\circ} \mathrm{K}$

$c_{p(f)}, \bar{c}_{p}=$ specific heat at $T_{f}$, and mean specific heat,

$n_{1} \quad T_{o}$ to $T_{f}$, respectively, cal $/{ }^{\circ} \mathrm{K} \mathrm{g}$

$\frac{n_{1}}{n_{2}}=$ moles of reactants $/$ moles of products

$D_{f}=$ diffusion coefficient at $T_{f}, \mathrm{~cm} / \mathrm{sec}$

$R=$ gas constant, cal $/ \mathrm{g}$ mole $-{ }^{\circ} \mathrm{K}$

$E=$ activation energy, cal $/ \mathrm{g}$ mole

$K=$ constant from the Arrhenius reaction rate equation

$a_{0}=$ number of molecules per unit volume of combustible in initial mixture.

Following Dugger's treatment [10], eq (7) reduces to

$$
S_{f} \propto\left(T_{0}^{2} T_{f}^{4.9} \frac{e^{-E / R T_{f}}}{\left(T_{f}-T_{o}\right)^{3}}\right)^{1 / 2} .
$$

The Tanford and Pease equation [11] for flame speed is

$$
S_{f}=\left(\Sigma_{i} p_{i} D_{i} k_{i} L \frac{Q^{\prime}}{Q B_{i}}\right)^{1 / 2}
$$

where

$p_{i}=$ mole fraction or partial pressure of a given active particle in the burnt gas

$D_{i}=$ the diffusion coefficient of the active particle into the unburnt gas

$k_{i}=\mathrm{a}$ rate constant for reaction of an active particle with the unburnt gas

$L=$ number of molecules per cubic centimeter of gas at some mean temperature

$Q^{\prime}=$ mole fraction of combustible in the unburnt gas

$Q=$ mole fraction of potential combustion product in the burnt gas

$B_{i}=$ term near unity, arising from radical recombination.
Again following Dugger, this is reduced to

$$
S_{f} \propto\left[\left(\Sigma p_{i} D_{i, \tau}\right) T_{0}^{1.67} T_{a v}{ }^{-1}\right]^{1 / 2}
$$

where $D_{i, r}$ is the relative diffusion coefficient of the given radical with respect to the other radicals, $T_{0}$ is the initial temperature, and $T_{a v}$ is the average of initial and flame temperature.

Flame temperatures were calculated by the method of Hottel, Williams, and Satterfield [12]. Equilibrium partial pressures of hydrogen atoms, hydroxyl radicals, and oxygen atoms were calculated by the method of Huff and Calvert [13]. The activation energy, $E$, was taken as $26 \mathrm{kcal} / \mathrm{g}$ mole [14].

In figure 15, where temperatures are in degrees Kelvin and flame speeds are in centimeters per second, curve $A B$ represents the experimental data; $A C$ is calculated by Semenov's equation; $A D$ is calculated from 'Tanford and Pease's equation, using $\Sigma p_{i} D_{i, r}=6.5 p_{\mathrm{H}}+p_{\mathrm{OH}}+p_{\mathrm{O}}$, and $A E$ is calculated from Tanford and Pease's equation considering only $p_{\mathrm{H}}$. Only the shape of the curves can be calculated; the calculation of absolute values of flame speeds depends on too many quantities that are uncertain or even unknown. The Semenov equation reproduces the shape of the experimental curve well, although it tends to diverge as the initial temperature increases. At $434.9^{\circ} \mathrm{K}$, the divergence amounts to about 5 percent. Curves $A D$ and $A E$ from Tanford and Pease's equation are almost coincident, but the fit to the experimental data is not as good. At $434.9^{\circ} \mathrm{K}$, there is a divergence of about 15 percent from the experimental curve.

The thermal theory thus appears to predict the effect of initial temperature on flame speed better than does the diffusion theory. However, as rather drastic assumptions were made in applying both

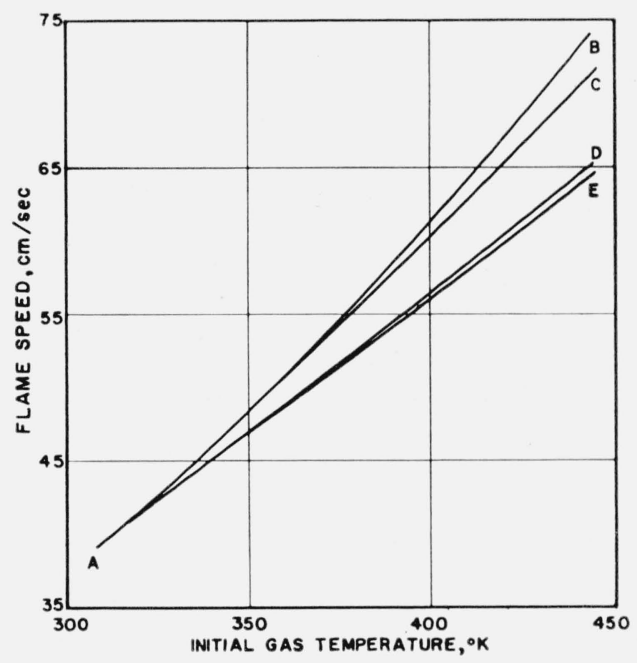

Figure 15. Comparison of experimental values with those calculated from equations of Semenov and of Tanford and Pease. .:.

$A B$ represents NBS; $A C$, Semenov; $A D$, Tanford and Pease, $6.5 p_{\mathrm{H}}+p_{\mathrm{O}}+p_{\mathrm{OH}}$; $A E$, Tanford and Pease, $p_{\text {H }}$ only, 
theories, it is possible that they were more favorable to Semenov's equation. Selection of the preferred theory from the data presented here therefore should be made with caution, if at all.

\section{Experimental Observations}

Observations of the effects of some variables on the flame are presented in detail in tables 2 to 7 .

TABLE 2. Variation of diameter of base of schlieren cone with gas velocity, at $75^{\circ} \mathrm{F}$, fuel-air ratio $=0.058$

\begin{tabular}{|c|c|c|c|}
\hline $\begin{array}{c}\text { Gas } \\
\text { velocity }\end{array}$ & $\begin{array}{c}\text { Diameter } \\
\text { of base of } \\
\text { schlieren } \\
\text { cone }\end{array}$ & $\begin{array}{c}\text { Gas } \\
\text { velocity }\end{array}$ & $\begin{array}{l}\text { Diameter } \\
\text { of base of } \\
\text { schlieren } \\
\text { cone }\end{array}$ \\
\hline $\begin{array}{l}\text { fps } \\
3 \\
4\end{array}$ & $\begin{array}{r}\text { in. } \\
0.577 \\
.551\end{array}$ & $\begin{array}{l}f p s \\
5 \\
6\end{array}$ & $\begin{array}{c}\text { in. } \\
0.539 \\
.526\end{array}$ \\
\hline
\end{tabular}

TABLE 3. Variation of diameter of base of schlieren cone with fuel-air ratio, at $75^{\circ} \mathrm{F}$, gas velocity $=6 \mathrm{fps}$

\begin{tabular}{|c|c|c|c|}
\hline $\begin{array}{l}\text { Fuel-air } \\
\text { ratio }\end{array}$ & $\begin{array}{c}\text { Diameter } \\
\text { of base of } \\
\text { schlieren } \\
\text { cone }\end{array}$ & $\begin{array}{l}\text { Fuel-air } \\
\text { ratio }\end{array}$ & $\begin{array}{l}\text { Diameter } \\
\text { of base of } \\
\text { schlieren } \\
\text { cone }\end{array}$ \\
\hline $\begin{array}{r}0.057 \\
.058 \\
.059 \\
.060 \\
.061 \\
.062\end{array}$ & $\begin{array}{c}i n . \\
0.525 \\
.523 \\
.527 \\
.526 \\
.527 \\
.528\end{array}$ & $\begin{array}{r}0.063 \\
.064 \\
.065 \\
.066 \\
.067\end{array}$ & $\begin{array}{c}\text { in. } \\
0.529 \\
.529 \\
.530 \\
.529 \\
.531\end{array}$ \\
\hline
\end{tabular}

TABLE 4. Variation of flame speed with gas velocity at $112.3^{\circ} \mathrm{F}$, fuel-air ratio $=0.062$

\begin{tabular}{|c|c|c|c|}
\hline $\begin{array}{c}\text { Gas } \\
\text { velocity }\end{array}$ & $\begin{array}{l}\text { Flame } \\
\text { speed }\end{array}$ & $\begin{array}{c}\text { Gas } \\
\text { velocity }\end{array}$ & $\begin{array}{l}\text { Flame } \\
\text { speed }\end{array}$ \\
\hline \multicolumn{4}{|c|}{ (a) Perfect cone technique } \\
\hline $\begin{array}{l}\text { fps } \\
3 \\
4 \\
5\end{array}$ & $\begin{array}{c}f p s \\
1.362 \\
1.353 \\
1.354\end{array}$ & $\begin{array}{l}\text { fps } \\
6 \\
7\end{array}$ & $\begin{array}{r}f p s \\
1.350 \\
1.342\end{array}$ \\
\hline \multicolumn{4}{|c|}{ (b) Planimeter technique } \\
\hline $\begin{array}{l}3 \\
4 \\
5\end{array}$ & $\begin{array}{l}\text { 1. } 370 \\
\text { 1. } 366 \\
1.373\end{array}$ & $\begin{array}{l}6 \\
7\end{array}$ & $\begin{array}{l}\text { 1. } 360 \\
\text { 1. } 347\end{array}$ \\
\hline
\end{tabular}

TABLE 5. Variation of flame speed with temperature fuel-air ratio $=0.062$, gas velocity $=6 \mathrm{fps}$

\begin{tabular}{|c|c||c|c|}
\hline $\begin{array}{c}\text { Tempera- } \\
\text { ture }\end{array}$ & $\begin{array}{c}\text { Flame } \\
\text { speed }\end{array}$ & $\begin{array}{c}\text { Tempera- } \\
\text { ture }\end{array}$ & $\begin{array}{c}\text { Flame } \\
\text { speed }\end{array}$ \\
\cline { 2 - 3 } & & & \\
& $f p s$ & $\circ F$ & $f p s$ \\
102.7 & 1.316 & 220.7 & 1.819 \\
120.6 & 1.376 & 240.3 & 1.910 \\
138.3 & 1.443 & 262.4 & 2.028 \\
159.7 & 1.550 & 280.4 & 2.121 \\
181.1 & 1.632 & 298.7 & 2.196 \\
203.6 & 1.754 & 323.1 & 2.379 \\
& & & \\
\hline
\end{tabular}

TABLE 6. Variation of flame speed with mixture ratio

\begin{tabular}{|c|c|c|c|}
\hline $\begin{array}{l}\text { Fuel-air } \\
\text { ratio }\end{array}$ & $\begin{array}{l}\text { Flame } \\
\text { speed }\end{array}$ & $\begin{array}{l}\text { Fuel-air } \\
\text { ratio }\end{array}$ & $\begin{array}{l}\text { Flame } \\
\text { speed }\end{array}$ \\
\hline \multicolumn{4}{|c|}{ a. Gas temperature $=84.4^{\circ} \mathrm{F}$; gas velocity $=6 \mathrm{fps}$} \\
\hline & fps & & fps \\
\hline $\begin{array}{l}0.0551 \\
.0561\end{array}$ & $\begin{array}{l}\text { 1. } 094 \\
1.156\end{array}$ & $\begin{array}{l}0.06659 \\
0659\end{array}$ & $\begin{array}{l}1.223 \\
1.190\end{array}$ \\
\hline .0580 & $\begin{array}{l}\text { 1. } 188 \\
\text { lo }\end{array}$ & .0680 & 1.148 \\
\hline .0600 & 1. 219 & .0701 & 1. 094 \\
\hline .0619 & 1. 233 & .0720 & 1.017 \\
\hline
\end{tabular}

b. Gas temperature $100^{\circ} \mathrm{F}$

\begin{tabular}{l|l||c|c}
\hline 0.0542 & 1.145 & 0.0640 & 1.271 \\
.0560 & 1.201 & .0661 & 1.240 \\
.0581 & 1.242 & .0681 & 1.186 \\
.0601 & 1.269 & .0701 & 1.135 \\
.0621 & 1.283 & .0720 & 1.064 \\
\hline \multicolumn{3}{|c}{ c. Gas temperature $120^{\circ} \mathrm{F}$} \\
\hline \multicolumn{3}{|c}{} \\
\hline 0521 & 1.150 & 0.0640 & 1.353 \\
.0541 & 1.235 & .0659 & 1.321 \\
.0560 & 1.290 & .0682 & 1.268 \\
.0589 & 1.336 & .0700 & 1.195 \\
.0620 & 1.357 & .0721 & 1.119 \\
\hline
\end{tabular}

d. Gas temperature $280^{\circ} \mathrm{F}$

(1) Gas velocity $=4 \mathrm{fps}$

\begin{tabular}{r|l||l|l}
\hline 0.0541 & 1.958 & 0.0641 & 2.211 \\
.0561 & 2.044 & .0661 & 2.183 \\
.0580 & 2.134 & .0681 & 2.131 \\
.0601 & 2.180 & .0703 & 2.054 \\
.0622 & 2.208 & .0721 & 1.957 \\
\hline
\end{tabular}

(2) Gas velocity $=5$ fps

\begin{tabular}{r|r||r|r}
\hline 0.0544 & 1.951 & 0.0643 & 2.197 \\
.0564 & 2.051 & .0663 & 2.176 \\
.0582 & 2.122 & .0683 & 2.104 \\
.0603 & 2.176 & .0703 & 2.008 \\
.0624 & 2.198 & .0724 & 1.890 \\
\hline
\end{tabular}

(3) Gas velocity $=6 \mathrm{fps}$

\begin{tabular}{r|r||r|r}
\hline 0.0537 & 1.875 & 0.0636 & 2.161 \\
.0558 & 1.997 & .0658 & 2.135 \\
.0577 & 2.059 & .0677 & 2.084 \\
.0597 & 2.128 & .0698 & 2.001 \\
.0618 & 2.161 & .0718 & 1.887 \\
\hline
\end{tabular}

(4) Gas velocity $=7 \mathrm{fps}$

\begin{tabular}{r|r|r|r|}
\hline 0.0539 & 1.916 & 0.0639 & 2.176 \\
.0559 & 2.026 & .0659 & 2.162 \\
.0579 & 2.101 & .0679 & 2.091 \\
.0599 & 2.141 & .0700 & 1.990 \\
.0619 & 2.186 & .0720 & 1.870 \\
\hline
\end{tabular}

e. Gas temperature $330^{\circ} \mathrm{F}$

(1) Gas velocity $=5 \mathrm{fps}$

\begin{tabular}{r|l||l|l}
\hline 0.0540 & 2.284 & 0.0640 & 2.431 \\
.0560 & 2.347 & .0661 & 2.378 \\
.0580 & 2.414 & .0680 & 2.308 \\
.0600 & 2.447 & .0700 & 2.186 \\
.0620 & 2.468 & .0720 & 2.013 \\
\hline
\end{tabular}

(2) Gas velocity $=6 \mathrm{fps}$

\begin{tabular}{r|r||r|r}
0.0537 & 2.122 & 0.0640 & 2.397 \\
.0560 & 2.223 & .0660 & 2.364 \\
.0580 & 2.286 & .0680 & 2.343 \\
.0600 & 2.350 & .0700 & 2.259 \\
.0620 & 2.407 & .0720 & 2.140
\end{tabular}


TABLE 6. Variation of flame speed with mixture ratio-Con.

\begin{tabular}{|c|c|c|c|}
\hline $\begin{array}{l}\text { Fuel-air } \\
\text { ratio }\end{array}$ & $\begin{array}{l}\text { Flame } \\
\text { speed }\end{array}$ & $\begin{array}{l}\text { Fuel-air } \\
\text { ratio }\end{array}$ & $\begin{array}{l}\text { Flame } \\
\text { speed }\end{array}$ \\
\hline \multicolumn{4}{|c|}{ (3) Gas velocity $=7 \mathrm{fps}$} \\
\hline $\begin{array}{r}0.0540 \\
.0560 \\
.0581 \\
.0600 \\
.0620\end{array}$ & $\begin{array}{l}2.178 \\
2.299 \\
2.367 \\
2.410 \\
2.425\end{array}$ & $\begin{array}{r}0.0640 \\
.0661 \\
.0681 \\
.0701 \\
.0721\end{array}$ & $\begin{array}{l}2.419 \\
2.383 \\
2.306 \\
2.212 \\
2.079\end{array}$ \\
\hline \multicolumn{4}{|c|}{ (4) Gas velocity $=8 \mathrm{fps}$} \\
\hline $\begin{array}{r}0.0541 \\
.0560 \\
.0580 \\
.0600 \\
.0621\end{array}$ & $\begin{array}{l}2.153 \\
2.257 \\
2.336 \\
2.375 \\
2.403\end{array}$ & $\begin{array}{r}0.0640 \\
.0660 \\
.0680 \\
.0700 \\
.0721\end{array}$ & 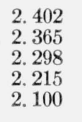 \\
\hline \multicolumn{4}{|c|}{ (5) Gas velocity $=9 \mathrm{fps}$} \\
\hline $\begin{array}{r}0.0541 \\
.0560 \\
.0580 \\
.0600 \\
.0620\end{array}$ & $\begin{array}{l}2.109 \\
2.197 \\
2.303 \\
2.336 \\
2.367\end{array}$ & $\begin{array}{r}0.0640 \\
.0660 \\
.0680 \\
.0701 \\
.0721\end{array}$ & $\begin{array}{l}2.369 \\
2.329 \\
2.270 \\
2.181 \\
2.072\end{array}$ \\
\hline \multicolumn{4}{|c|}{ (6) Gas velocity $=10.2 \mathrm{fps}$} \\
\hline $\begin{array}{r}0.0562 \\
.0580 \\
.0600 \\
.0620 \\
.0640\end{array}$ & $\begin{array}{l}2.236 \\
2.308 \\
2.350 \\
2.365 \\
2.358\end{array}$ & $\begin{array}{r}0.0660 \\
.0680 \\
.0700 \\
.0721\end{array}$ & $\begin{array}{l}2.341 \\
2.283 \\
2.218 \\
2.120\end{array}$ \\
\hline
\end{tabular}

TABLE 7. Variation of flame speed with gas velocity

\begin{tabular}{|c|c|c|c|c|c|}
\hline $\begin{array}{c}\text { Gas } \\
\text { velocity }\end{array}$ & $\begin{array}{l}\text { Flame } \\
\text { speed }\end{array}$ & $\begin{array}{l}\text { Fuel-air } \\
\text { ratio }\end{array}$ & $\begin{array}{c}\text { Gas } \\
\text { velocity }\end{array}$ & $\begin{array}{l}\text { Flame } \\
\text { speed }\end{array}$ & $\begin{array}{l}\text { Fuel-air } \\
\text { ratio }\end{array}$ \\
\hline \multicolumn{6}{|c|}{ a. Gas temperature $280^{\circ} \mathrm{F}$} \\
\hline $\begin{array}{r}f p s \\
4 \\
5\end{array}$ & $\begin{array}{c}f p s \\
1.958 \\
1.951\end{array}$ & 0.054 & $\begin{array}{r}f p s \\
6 \\
7\end{array}$ & $\begin{array}{c}f p s \\
1.875 \\
1.916\end{array}$ & 0.054 \\
\hline $\begin{array}{l}4 \\
5\end{array}$ & $\begin{array}{l}2.044 \\
\text { 2. } 051\end{array}$ & .056 & $\begin{array}{l}6 \\
7\end{array}$ & $\begin{array}{l}1.997 \\
2.026\end{array}$ & .056 \\
\hline $\begin{array}{l}4 \\
5\end{array}$ & $\begin{array}{l}2.134 \\
\text { 2. } 122\end{array}$ & .058 & $\begin{array}{l}6 \\
7\end{array}$ & $\begin{array}{l}2.059 \\
\text { 2. } 101\end{array}$ & .058 \\
\hline $\begin{array}{l}4 \\
5\end{array}$ & $\begin{array}{l}2.180 \\
\text { 2. } 176\end{array}$ & .060 & $\begin{array}{l}6 \\
7\end{array}$ & $\begin{array}{l}2.1 \angle 8 \\
\text { 2. } 141\end{array}$ & .060 \\
\hline $\begin{array}{l}4 \\
5\end{array}$ & $\begin{array}{l}2.208 \\
\text { 2. } 198\end{array}$ & .062 & $\begin{array}{l}5 \\
7\end{array}$ & $\begin{array}{l}2.161 \\
2.186\end{array}$ & .062 \\
\hline $\begin{array}{l}4 \\
5\end{array}$ & $\begin{array}{l}\text { 2. } 211 \\
\text { 2. } 197\end{array}$ & .064 & $\begin{array}{l}6 \\
7\end{array}$ & $\begin{array}{l}2.161 \\
\text { 2.176 }\end{array}$ & .064 \\
\hline $\begin{array}{l}4 \\
5\end{array}$ & $\begin{array}{l}2.183 \\
\text { 2. } 176\end{array}$ & .066 & $\begin{array}{l}6 \\
7\end{array}$ & $\begin{array}{l}2.135 \\
2.162\end{array}$ & .066 \\
\hline $\begin{array}{l}4 \\
5\end{array}$ & $\begin{array}{l}2.131 \\
2.104\end{array}$ & .068 & $\begin{array}{l}6 \\
7\end{array}$ & $\begin{array}{l}2.084 \\
\text { 2. } 091\end{array}$ & .068 \\
\hline $\begin{array}{l}4 \\
5\end{array}$ & $\begin{array}{l}2.054 \\
2.008\end{array}$ & .070 & $\begin{array}{l}6 \\
7\end{array}$ & $\begin{array}{l}2.001 \\
1.990\end{array}$ & .070 \\
\hline $\begin{array}{l}4 \\
5\end{array}$ & $\begin{array}{l}1.957 \\
1.890\end{array}$ & .072 & $\begin{array}{l}6 \\
7\end{array}$ & $\begin{array}{l}\text { 1. } 887 \\
1.870\end{array}$ & .072 \\
\hline
\end{tabular}

TABLE 7. Variation of flame speed with gas velocity-Con

\begin{tabular}{|c|c|c|c|c|c|}
\hline $\begin{array}{c}\text { Gas } \\
\text { velocity }\end{array}$ & $\begin{array}{l}\text { Flame } \\
\text { speed }\end{array}$ & $\begin{array}{l}\text { Fuel-air } \\
\text { ratio }\end{array}$ & $\begin{array}{c}\text { Gas } \\
\text { velocity }\end{array}$ & $\begin{array}{l}\text { Flame } \\
\text { speed }\end{array}$ & $\begin{array}{l}\text { Fuel-air } \\
\text { ratio }\end{array}$ \\
\hline \multicolumn{6}{|c|}{ b. Gas temperature $330^{\circ} \mathrm{F}$} \\
\hline $\begin{array}{c}f p s \\
5 \\
6 \\
7\end{array}$ & $\begin{array}{c}f p s \\
2.284 \\
2.122 \\
2.178\end{array}$ & 0.054 & $\begin{array}{r}f p s \\
8 \\
9\end{array}$ & $\begin{array}{c}f p s \\
2.153 \\
2.109\end{array}$ & 0.054 \\
\hline $\begin{array}{l}5 \\
6 \\
7\end{array}$ & $\begin{array}{l}2.347 \\
2.223 \\
2.299\end{array}$ & .056 & $\begin{array}{c}8 \\
9 \\
10.2\end{array}$ & $\begin{array}{l}\text { 2. } 257 \\
\text { 2. } 197 \\
\text { 2. } 236\end{array}$ & .056 \\
\hline $\begin{array}{l}5 \\
6 \\
7\end{array}$ & $\begin{array}{l}2.415 \\
2.286 \\
2.367\end{array}$ & .058 & $\begin{array}{c}8 \\
9 \\
10.2\end{array}$ & $\begin{array}{l}2.336 \\
2.303 \\
2.308\end{array}$ & .058 \\
\hline $\begin{array}{l}5 \\
6 \\
7\end{array}$ & $\begin{array}{l}2.447 \\
2.350 \\
2.410\end{array}$ & .060 & $\begin{array}{c}8 \\
9 \\
10.2\end{array}$ & $\begin{array}{l}2.375 \\
2.336 \\
2.350\end{array}$ & .060 \\
\hline $\begin{array}{l}5 \\
6 \\
7\end{array}$ & $\begin{array}{l}2.468 \\
2.407 \\
2.425\end{array}$ & .062 & $\begin{array}{c}8 \\
9 \\
10.2\end{array}$ & $\begin{array}{l}2.403 \\
2.367 \\
2.365\end{array}$ & .062 \\
\hline $\begin{array}{l}5 \\
6 \\
7\end{array}$ & $\begin{array}{l}2.431 \\
2.397 \\
2.419\end{array}$ & .064 & $\begin{array}{c}8 \\
9 \\
10.2\end{array}$ & $\begin{array}{l}2.402 \\
2.369 \\
2.358\end{array}$ & .064 \\
\hline $\begin{array}{l}5 \\
6 \\
7\end{array}$ & $\begin{array}{l}2.377 \\
2.364 \\
2.383\end{array}$ & .066 & $\begin{array}{c}8 \\
9 \\
10.2\end{array}$ & $\begin{array}{l}2.365 \\
2.329 \\
2.341\end{array}$ & .066 \\
\hline $\begin{array}{l}5 \\
6 \\
7\end{array}$ & $\begin{array}{l}2.308 \\
2.343 \\
2.306\end{array}$ & .068 & $\begin{array}{c}8 \\
9 \\
10.2\end{array}$ & $\begin{array}{l}2.298 \\
2.270 \\
2.283\end{array}$ & .068 \\
\hline $\begin{array}{l}5 \\
6 \\
7\end{array}$ & $\begin{array}{l}2.186 \\
2.259 \\
2.212\end{array}$ & .070 & $\begin{array}{c}8 \\
9 \\
10.2\end{array}$ & $\begin{array}{l}2.215 \\
2.181 \\
2.218\end{array}$ & .070 \\
\hline $\begin{array}{l}5 \\
6 \\
7\end{array}$ & $\begin{array}{l}2.013 \\
2.140 \\
2.079\end{array}$ & .072 & $\begin{array}{c}8 \\
9 \\
10.2\end{array}$ & $\begin{array}{l}2.100 \\
2.072 \\
2.120\end{array}$ & .072 \\
\hline
\end{tabular}

\section{Conclusions}

The apparatus for determining flame speeds has been improved so that stable flames, free from oscillations, can be maintained on 1/2- and $3 / 4-i n$. nozzles at temperatures, measured in the throat of the nozzle, up to $330^{\circ} \mathrm{F}$. The size of the nozzles is such that there are no gross effects of the burner on flame speeds. Temperature of gas in the nozzle can be controlled to $\pm 0.5^{\circ} \mathrm{F}$. Calibration of the sharpedged orifices used to measure the flow of gases is now considered to be accurate to 0.5 percent.

Variation of flame speed with fuel-air ratio at constant gas velocity and constant inlet gas temperature has been determined for a range of temperatures up to $330^{\circ} \mathrm{F}$.

Dependence of flame speed on initial gas temperature at constant gas speed was determined and the result compared with that predicted by two theories of flame propagation.

Variation of flame speed, at constant temperature, with gas velocity has been reduced, (a) by using the area technique of measuring flame speed instead of the angle technique, and (b) by improvements in the quality of the flame. Two different methods of 
determining areas of the flame yield values of flame speeds that are in close agreement. From the study of photographs of flames, it was found that the diameter of the base of the schlieren cone increases as the fuel-air ratio increases, and decreases as the gas velocity increases. Conditions of flow in the nozzle during burning and quenching of flame by the nozzle undoubtedly are the cause of these effects. At an initial gas temperature of $112^{\circ} \mathrm{F}$, the variation of flame speed with gas velocity over the range of gas velocities from 3 to $7 \mathrm{fps}$ amounts to about 1.5 percent. This variation increases as the initial temperature increases.

Since there still remains some variation of flame speed with gas velocity, contrary to theoretical expectations, it is evident that the measurement of true burning velocity has not been achieved. However, in view of the relatively small variation remaining, it is reasonable to expect the values of flame speeds reported here approach closely the true burning velocity.

Gerry H. Morgan, now of the University of Connecticut, Storrs, Conn., did much of the early experimental work and contributed to the design of the apparatus. Many thanks are due Frank R. Caldwell for helpful discussions and encouragement.

\section{References}

[1] F. R. Caldwell, H. P. Broida, and J. J. Dover, Ind. Eng. Chem.43, 2731 (1951).

[2] G. H. Morgan and W. R. Kane, Fourth Symposium (International) on Combustion, p. 313 (Williams \& Wilkins, Baltimore, Md., 1953).

[3] W. C. Johnston, Soc. Automotive Engrs. J. 55, 62 (Dec. 1947).

[4] B. Lewis and G. von Elbe, J. Chem. Phys. 11, 75 (1943).

[5] M. Reiner, Phys. Today 9, 16 (Sept. 1956).

[6] R. E. Albright, D. P. Heath, and R. H. Thena, Ind. Eng. Chem. 44, 2490 (1952).

[7] B. Lewis and G. von Elbe, Combustion, flames, and explosions of gases, p. 238 (Academic Press, N. Y., N. Y., 1951).

[8] F. A. Smith and S. F. Pickering, J. Research NBS 17, 7 (1936) RP900.

[9] N. N. Semonov, Nat. Advisory Comm. Aeronaut. Tech. Mem. No. 1026 (1942).

[10] G. L. Dugger, J. Am. Chem. Soc. 72, 5271 (1950).

[11] C. Tanford and R. N. Pease, J. Chem. Phys. 15, 861 (1947).

[12] H. C. Hottel, G. C. Williams, and C. N. Satterfield, Thermodynamic charts for combustion processes (John Wiley \& Sons, New York, N. Y., 1949).

[13] V. N. Huff and C. S. Calvert, Nat. Advisory Comm. Aeronaut. Tech. Note No. 1653 (1948).

[14] J. B. Fenn and H. F. Calcote, Fourth Symposium (International) on Combustion, p. 231 (Williams \& Wilkins Co., Baltimore, Md., 1953).

Washington, December 5, 1957. 